\title{
Microbial Symbionts of Insects are the Focus of the First International Cooperative Biodiversity Group (ICBG) in Brazil
}

\author{
Mônica T. Pupo, ${ }^{*, a}$ Cameron R. Currie $e^{b}$ and Jon Clardy ${ }^{*, c}$ \\ ${ }^{a}$ Faculdade de Ciências Farmacêuticas de Ribeirão Preto, Universidade de São Paulo, \\ Avenida do Café, s/n, 14040-903 Ribeirão Preto-SP, Brazil \\ ${ }^{b}$ Department of Bacteriology, University of Wisconsin, 1550 Linden Drive, 53706 Madison-WI, USA \\ ${ }^{c}$ Department of Biological Chemistry and Molecular Pharmacology, Harvard Medical School, \\ 240 Longwood Ave., 02115 Boston-MA, USA
}

\begin{abstract}
The basic aim of the ICBG (International Cooperative Biodiversity Group) program is to benefit both the host country and the global scientific community by discovering and developing new solutions to human health problems based on previously unexplored genetic resources. The first ICBG in Brazil is jointly supported by the Fogarty International Center of the National Institutes of Health (FIC/NIH) in the USA and by the São Paulo Research Foundation (FAPESP) in Brazil. The ongoing ICBG, developed under the BIOTA-FAPESP Program, is based on the highly evolved fungus-growing ant multilateral symbiosis between three mutualists and one parasite. The project aligns chemical ecology and therapeutic application, increasing the chances of discovering new antifungal, antibacterial, anticancer and antiprotozoal hits and leads. In this article we describe the rationale of the ICBG and the legal requirements to develop this type of international collaborative project in Brazil.
\end{abstract}

Keywords: microbial symbionts, social insects, natural products, ICBG, international collaboration

\section{Introduction}

The John E. Fogarty International Center (FIC) of the US National Institutes of Health (NIH) created the International Cooperative Biodiversity Group (ICBG) program to promote collaborative research between US academic institutions and similar organizations in biodiverse countries. ${ }^{1}$ The ICBG program is supported by FIC, various NIH institutes, and other US funding agencies such as the National Science Foundation. The Brazilian ICBG has a unique feature: joint funding with Brazil, as described below. The basic aim of the ICBG program is to benefit both the host country and the global scientific community by discovering and developing new solutions to human health problems based on previously unexplored genetic resources. The program also promotes biodiversity conservation in the host country through encouraging and supporting sustainable practices for using biological resources.

*e-mail: mtpupo@fcfrp.usp.br; jon_clardy@hms.harvard.edu
FIC/NIH and São Paulo Research Foundation (FAPESP) signed a Memorandum of Understanding (MoU) in September, 2013 to join forces and strengthen US-Brazil scientific collaboration through the ICBG program. The agreement recognizes the importance of supporting joint research and other mutually beneficial activities in the pursuit of common scientific goals related to biodiversity exploration for potential applications in health. ${ }^{2} \mathrm{~A}$ call for joint proposals between the US and Brazil was opened on October, $2013^{3}$ and the result was announced by FIC/NIH and FAPESP on May, 2014. ${ }^{4}$

The first five-year ICBG project in Brazil, entitled "Novel therapeutic agents from the bacterial symbionts of Brazilian invertebrates", is part of the BIOTA-FAPESP Program. The ICBG's overall goal is to explore insect bacterial symbionts to discover novel natural products and develop potentially new antifungal, anticancer and antiprotozoal drug leads. Five Associated Programs (Figure 1) bringing together a team of chemists, biologists and physicians will achieve this overall goal by executing three general specific aims: $(i)$ explore and catalog bacterial 
strains from Brazilian insect-bacterial symbioses that are likely to produce highly selective growth inhibitory agents; (ii) analyze strains with metabolic, behavioral, and genetic tools to identify strains with the ability or the potential to produce diverse biologically active small molecules; (iii) identify candidates for therapeutic development as antifungal, anticancer or antiparasitic agents through focused primary and secondary screens. To achieve the ICBG goals, the research team is divided in five Associate Programs (AP). AP-1 in Brazil guided by Mônica T. Pupo and includes Adriano A. Andricopulo (IFSC-USP), Fabio S. do Nascimento (FFCLRP-USP) and André Rodrigues (Institute of Biosciences-UNESP) as co-investigators. University of Wisconsin-Madison houses three APs: AP-2, led by Timothy S. Bugni; AP-3, directed by Cameron R. Currie; and AP-4 coordinated by David R. Andes. AP-5 is directed by Jon Clardy (Harvard Medical School), and also includes Jun Qi (Dana Farber Cancer Institute) as coinvestigator. Figure 1 summarizes ICBG work flow.

In this article we describe the background and significance of the ICBG project as well as the legal steps required for this international collaboration.

\section{Natural Products in Drug Discovery}

The small molecules biosynthesized by plants, animals and microbes have played pivotal roles in drug discovery and development since ancient times. ${ }^{5}$ Despite this historical record of successful discovery, most pharmaceutical companies have discontinued their natural products programs in favour of high-throughput screening of chemically diverse synthetic compounds libraries. However, data about drugs approved by the US Food and Drug Administration (FDA) in the last 34 years show that natural products, their analogues and synthetic derivatives still play a significant role in therapeutics. ${ }^{6}$ The major impact of naturally-occurring small molecules in therapeutics is most clearly visible in cancer and infectious disease, especially bacterial infections. Naturally-occurring small molecules and their semi-synthetic derivatives represent $73 \%$ of the 112 drugs approved by the FDA as antibacterial agents from 1981-2014, while $40 \%$ of the 136 approved anticancer drugs in the same period constitute natural products and their semi-synthetic derivatives. The FDA data show that natural products and their semisynthetic derivatives comprise $22 \%$ of the anticancer drugs and $4.5 \%$ of the antibacterial agents approved more recently (2010-2014), confirming that naturally occurring small molecules continue to play an important role in recent drug development. ${ }^{6}$

The success of natural products in drug discovery is related to their evolutionary histories, the numerous rounds of modification, selection, and amplification that allows them to accomplish physiological and ecological functions for the producing organisms. ${ }^{5}$ However, it is still challenging to describe the specific functions of naturally-occurring small molecules for their producing organisms. Most newly discovered small molecules are identified by chemical and/or bioinformatic analyses that focus on structural novelty, and linking them to a biological function, much less a medically useful biological function, is postponed. Recent studies on symbiotic systems have described the functions of natural small molecules in mediating interactions between organisms, i.e., the context of their discovery provides clues as to biological function. In this way, an approach based on chemical ecology for

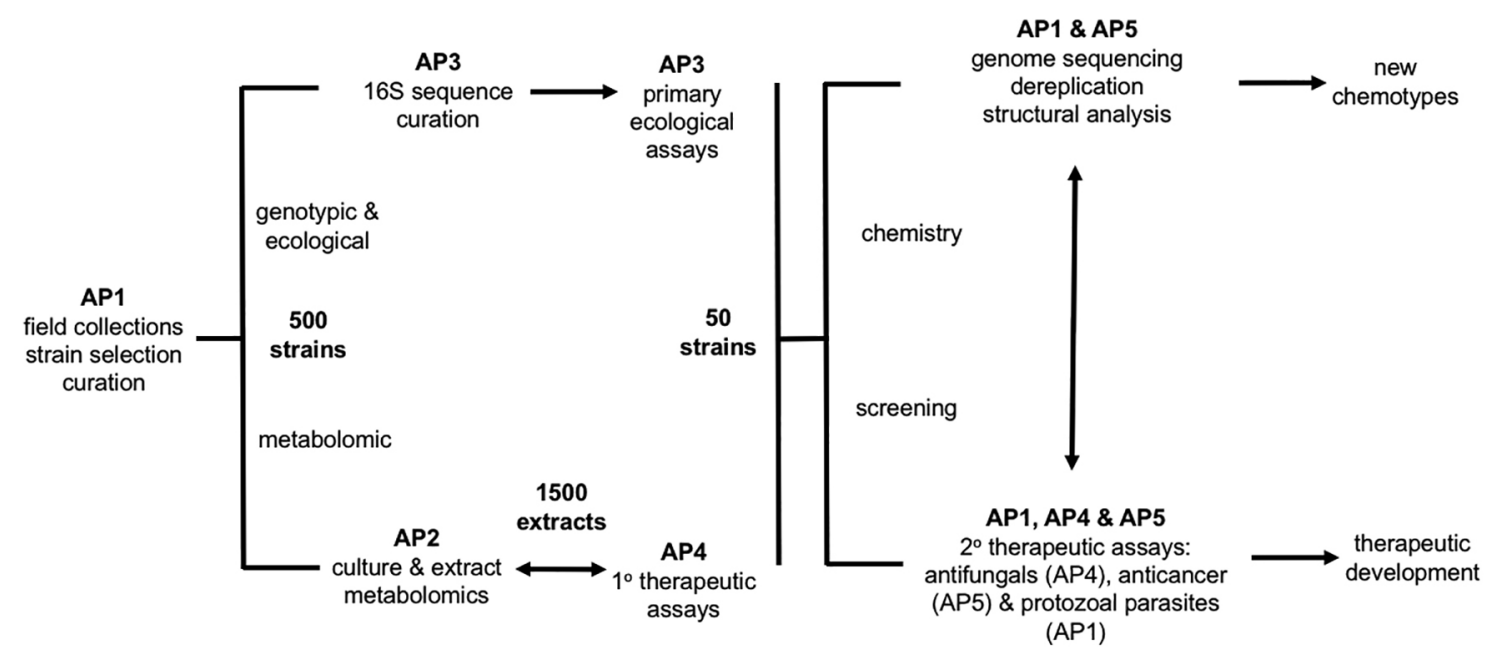

Figure 1. ICBG work flow and roles for each Associate Program (AP). Projects progress from left to right, from field collection in Brazil through molecular discovery and possible therapeutic development. Some APs are involved at different stages. Estimated numbers for initial years are shown in bold, and double headed arrows represent iterative processes like bioassay-guided fractionation. 
small molecule discovery may provide a rational approach to linking molecular discovery to therapeutic application and increase the chances of discovering therapeutic agents.

\section{Background on Microbial Symbionts of Ants}

Microorganisms comprise the majority of the world's biodiversity, and have established different types of interactions with humans, animals and plants, including essential mutualisms. As a result, the metabolic potential of all animals is the sum of their own genetic endowment plus that of all of their resident microbes. ${ }^{7}$ The metabolic capabilities of microorganisms enable hosts to access chemical diversity unavailable from their genomes; therefore, the exploitation of microbial symbionts might lead to chemical innovation and understanding of evolution.

Some insects, including ants of the myrmicine tribe Attini, macrotermitine termites and certain wood-boring beetles share the agricultural habit of culturing and eating fungi. ${ }^{8}$ It is accepted that ant fungus-growers originated only once in a single ancestral attine in Amazon some 45 million years ago. In Africa, southern Asia, and other parts of the Old World tropics, the Attini are replaced by fungus-growing termites (Macrotermitinae) ${ }^{9}$ The attine ant system diversified into more than 200 species, including the leaf-cutters, which are major herbivores in the Neotropics. ${ }^{8}$

The ICBG project is based on the highly evolved fungus-growing ant quadripartite symbiosis between three mutualists and one parasite. ${ }^{10}$ Attine ants collect plant and other material they forage from the environment to nourish fungal gardens they cultivate for food. Two additional players act in this symbiotic system: a specific pathogenic fungus from the genus Escovopsis, which can suppress the crop fungal cultivar and consequently exterminate the ant colony, ${ }^{11}$ and a symbiotic bacterium belonging to the genus Pseudonocardia (Actinobacteria) that live in ant crypts. ${ }^{12,13}$ The bacteria produce small molecules that selectively inhibit the pathogenic fungus but not the crop fungus (Figure 2).

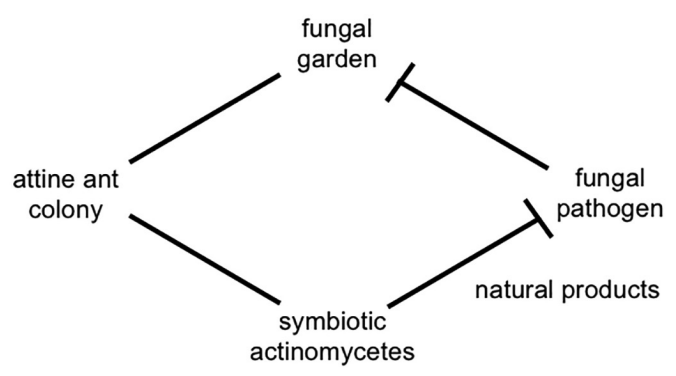

Figure 2. Interactions in the quadripartite symbiosis of fungus-farming ant colonies. Lines represent mutualisms and T-figures represent antagonism.
Natural products that mediate this complex symbiotic system have been barely studied and offer unique opportunities for the discovery of new biologically active small molecules. ${ }^{14}$ Dentigerumycin (1) represents the first compound structurally and functionally characterized to selectively suppress the pathogenic fungus Escovopsis (Figure 3). ${ }^{15}$ This cyclic depsipeptide is produced by the symbiotic Pseudonocardia, isolated from the exoskeleton of Apterostigma dentigerum. Dentigerumycin also shows antifungal activity against Candida albicans wild type, C. albicans ATCC10231 and amphotericin-resistant $C$. albicans ATCC200955. ${ }^{15}$ More recently, new dentigerumycin analogues lacking the polyketide moiety, gerumycins A-C (2-4), have been isolated from Pseudonocardia strains also associated with Apterostigma ants collected in Panama and Costa Rica (Figure 3). Compounds 2-4 are less potent than dentigerumycin (1) at suppressing Escovopsis growth. ${ }^{16}$ Detailed analysis of the biosynthetic gene clusters encoding the production of 1-4 revealed that different biosynthetic architectures, including genomic islands, a plasmid, and the use of spatially separated genetic loci, can lead to molecules with almost identical core structures. The results reveal the importance of a plasmid-based strategy of recently acquired DNA for the transmission and evolution of molecular diversity in a specialized niche, evidencing how genomic studies can help the understanding of the evolutionary history of genetically encoded small molecules and how ant-associated bacteria acquire and evolve new molecules.

Intriguingly, some Pseudonocardia strains isolated from different colonies of $A$. dentigerum can inhibit the growth of other Pseudonocardia strains isolated from different colonies, showing a possible competition among strains for establishing the symbiotic relationship with an ant colony. Subsequent studies lead to the discovery of 9-methoxyrebeccamycin (5), a new indolocarbazole with potent activity against a panel of Pseudonocardia (Figure 3). This compound has several analogues that have been tested in clinical trials for different cancer types. ${ }^{17}$

Three new angucyclines, pseudonocardones A-C (68), have been isolated from Pseudonocardia associated to $A$. dentigerum, together with the previously known 6-deoxy-8-O-methylrabelomycin (9) and X-14881 E (10) (Figure 3). Compounds $\mathbf{9}$ and $\mathbf{1 0}$ showed antibiotic and antimalarial activities..$^{18}$

The characterization of natural products from attine bacterial symbionts in Brazil includes the identification of urauchimycins A (11) and B (12) (Figure 3), antifungal antimycins produced by Streptomyces sp. TD025 isolated from Trachymyrmex ants. ${ }^{19}$

Ant bacterial symbionts have been poorly studied so far and their biosynthetic potential is basically unexplored. 
In previous joint research, Clardy and Currie laboratories have pioneered the identification of new biologically active small molecules from this system. Therefore, there are fruitful opportunities for natural product discovery from the attine bacterial symbionts isolated in Brazil. Indeed, ICBG initial efforts have led to about 40 attine nests collected in Cerrado and Atlantic Forrest areas, from which hundreds of microbial strains have been isolated and are currently being studied in our laboratories.

\section{Other Insect-Microbial Symbioses}

Fungus-growing termites (Macrotermitinae: single
Termitidae subfamily) also establish mutualistic symbiosis with a basidiomycete fungus of the genus Termitomyces. Termites are benefited by the fungus, which is food source and also helps insects in degradating plant material. ${ }^{20}$ Pseudoxylaria and Trichoderma are potential fungal antagonists against Termitomyces. Bacillaene A (13) was isolated from a Bacillus sp. strain isolated from colonies of Macrotermes natalensis and showed a selective inhibition against the fungi Pseudoxylaria and Trichoderma (Figure 4). Compound 13 inhibited the fungi Coriolopsis sp., Umbelopsis sp. and Fusarium sp., all considered as other possible competitors isolated from the same colony. ${ }^{21}$ A new antifungal macrolide named natalamycin A (14),

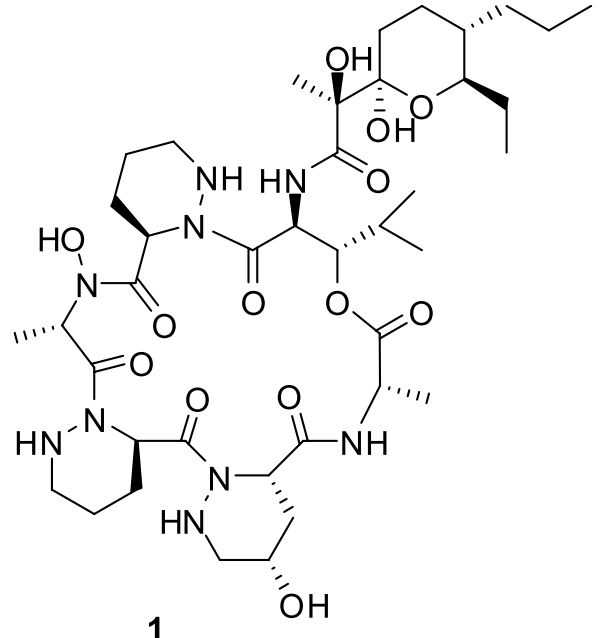

1<smiles>COc1cccc2c1C(=O)c1ccc3cc(C)cc(OC(C(=O)O)C(C)(CO)C(O)C(O)C(O)C(=O)O)c3c1C2O</smiles>

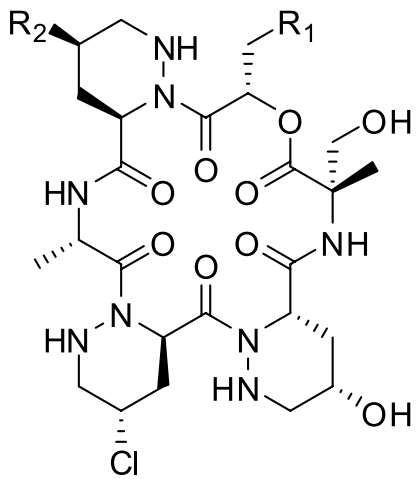

$2 \mathrm{R}_{1}=\mathrm{H} ; \mathrm{R}_{2}=\mathrm{H}$ $3 \mathrm{R}_{1}=\mathrm{CH}_{3} ; \mathrm{R}_{2}=\mathrm{H}$ $4 \mathrm{R}_{1}=\mathrm{H} ; \mathrm{R}_{2}=\mathrm{OH}$<smiles></smiles>

5<smiles></smiles>

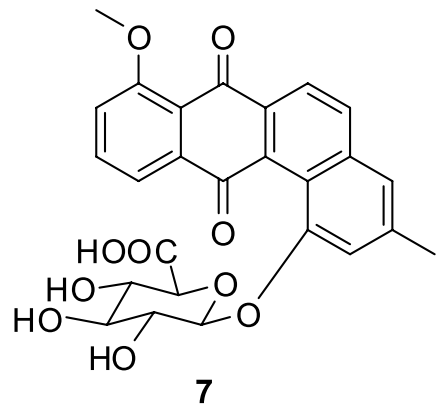<smiles>COc1cccc2c1C(=O)c1ccc3cc(C)cc(O)c3c1C2=O</smiles>

10<smiles>[Y][R](=C)C=[R]([R2])[R2]#[Y]</smiles>

Figure 3. Structures of new (1-8) and known (9-12) bioactive compounds from ant-associated actinobacteria. 
together with other analogues, have been isolated from a Streptomyces sp. symbiont of Macrotermes natalensis Mn802 (Figure 4). ${ }^{22}$ Microtermolides A (15) and B (16) are two new PKS-NRPS hybrids isolated from a Streptomyces strain associated with Microtermes sp. (Figure 4). ${ }^{23}$

Studies on different fungus-feeding insect symbiont systems have also demonstrated the untapped potential for the discovery of new biologically active small molecules. The Southern pine beetle, Dendroctonus frontalis, has a beneficial symbiosis with the fungus Entomocorticium sp. A, which provides food for their developing larvae. The antagonistic fungus Ophiostoma minus can displace Entomocorticium sp. A and thereby disrupt beetle larval development. ${ }^{24}$ The D. frontalis-Entomocorticium sp. A mutualism is mediated by Streptomyces sp. SPB74, which produces mycangimycin (17) (Figure 5). ${ }^{24,25}$ This novel polyene peroxide $\mathbf{1 7}$ controls growth of the antagonistic fungus $O$. minus and protects the larval food fungus Entomocorticium sp. A. Mycangimycin also inhibits different Candida albicans strains and has a potent activity against Plasmodium falciparum. ${ }^{25}$ Two new polycyclic tetramate macrolactams, frontalamides A (18) and B (19), were also discovered from Streptomyces sp. SPB78 isolated from same beetle (Figure 5). ${ }^{26}$

Similar symbiotic systems associated with social bees have scarcely been investigated yet. Pioneer studies in Brazil have recently reported that the Brazilian social stingless bee Scaptotrigona depilis cultivate a fungus to survive. ${ }^{27}$ This fungus grows inside the brood cell as food for the larvae. The mechanism of defense that may control growth of pathogenic microorganisms in this system is unknown. ${ }^{27}$ This finding opens an unprecedented opportunity for chemical-ecology guided studies in the search of natural products that might be involved in the mediation of microbial interactions and microbial-host interactions in S. depilis, and possibly other colonies of stingless bees. Indeed, ICBG efforts also have been focusing on $S$. depilis associated microbiota. The whole-genome sequencing of Bacillus sp. SDLI1, which was isolated from inside the larvae, harbours biosynthetic gene clusters for the production of antimicrobial compounds. ${ }^{28}$
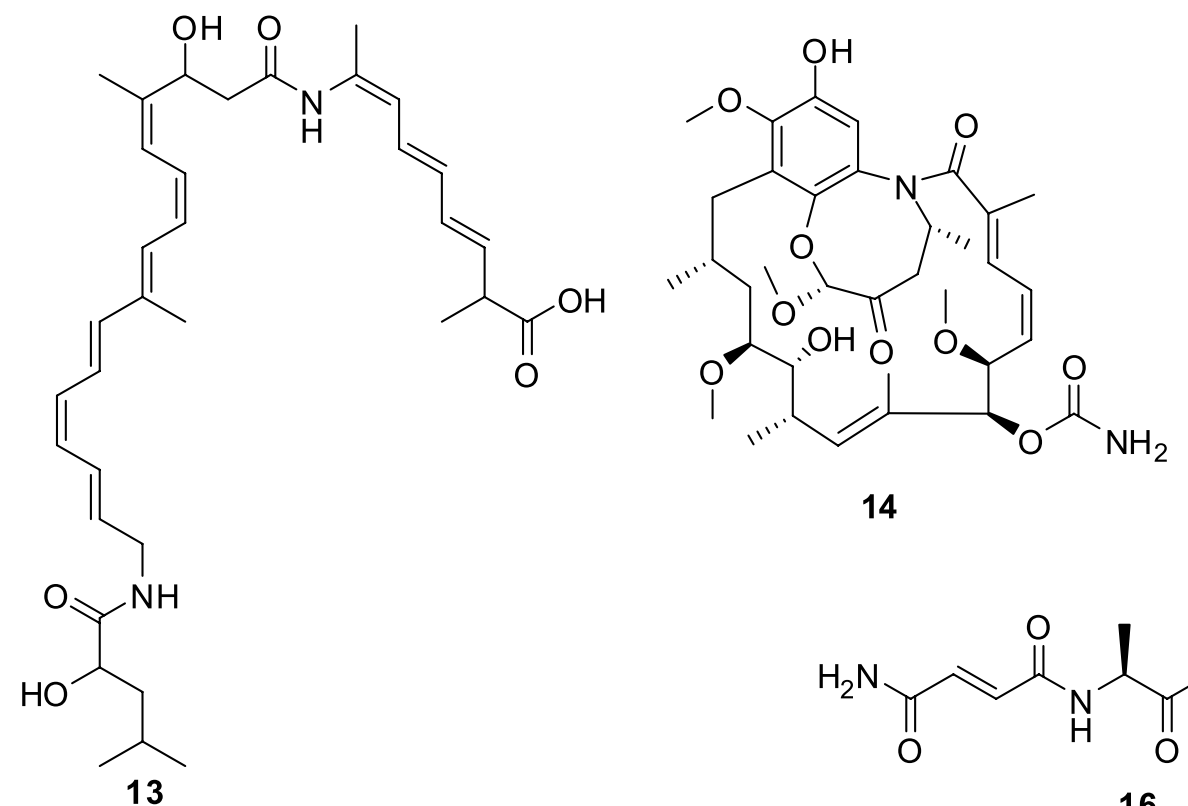<smiles>C=C(/C=C/C(=O)NC[C@H](C)C(=O)N[C@@H](C(=O)O[C@@H](C(C)C)[C@@H](C)CCC)[C@@H](C)CCO)NC(=O)C(C)C</smiles>

15<smiles>CCC[C@H](C)[C@H](OC(=O)[C@H](NC(=O)[C@H](C)NC(=O)/C=C/C(N)=O)C(C)C)[C@@H]1CCOC1=O</smiles>

Figure 4. Biologically active natural products isolated from microorganisms associated with termites.<smiles>C=C/C=C/C=C\C=C\C=C\C=C/C=C\CC1C[C@@H](CC(=O)O)OO1</smiles>

17

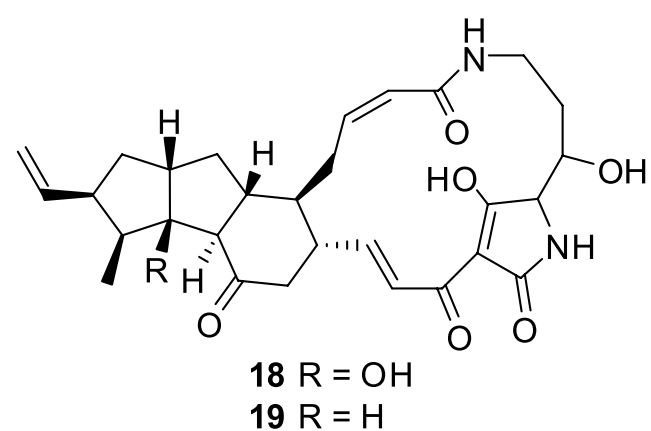

$18 \mathrm{R}=\mathrm{OH}$

Figure 5. Structures of new natural products isolated from actinobacteria associated to the southern pine beetle Dendroctonus frontalis. 
The ongoing studies in our laboratories will further clarify the roles of microorganisms and their natural products in S. depilis.

\section{The Need for Antifungal, Anticancer and Antiprotozoal Agents}

The ICBG project aligns ecological function and therapeutic function, increasing the chances of discovering new drug candidates. The project has a primary focus on antifungal agents, as a direct result of the specific role of the small molecules in their natural habitat, and a secondary focus on anticancer and antiprotozoal agents. There is functional connection between antifungal agents and anticancer agents, both must selectively kill some eukaryotic cells while sparing other eukaryotic cells. A remarkable example of this connection is rapamycin (Sirolimus), a transplant drug that was first discovered as an antifungal agent produced by soil bacteria. Rapamycin is also being tested as an anticancer agent. ${ }^{29}$

There is an urgent need for new drugs against fungal and parasitic diseases, as well as a continuous need for agents with new mechanisms of action to treat cancer.

Fungi are the planet's biggest killers, causing more than $70 \%$ of the recorded global and regional extinction events, and emerging fungal diseases threaten humans, other animals, and plants. ${ }^{30}$ Nevertheless, fungal diseases receive little attention from the World Health Organization (WHO) and other public health agencies compared to bacterial and viral diseases. Invasive fungal infections have a lower incidence than superficial infections; however millions of people worldwide get life-threatening invasive infections that are both difficult to diagnose and difficult to treat. ${ }^{31} \mathrm{~A}$ major issue in these fungal infections is their high mortality rate, which is often higher than $50 \%$ and frequently exceeds $90 \%$. Worldwide, invasive fungal infections kill about 1.5 million people annually, compared to tuberculosis (1.3 million worldwide mortality, WHO), HIV-AIDS (1.7 million, WHO), and malaria (0.6 million, WHO). Candida, Cryptococcus, Aspergillus and Pneumocystis are the four fungal genera responsible for most of the infections, and incidence increases in aging population and immunocompromised individuals. Despite treatment, mortality rates of fungal infections in AIDS patients range from $15-20 \%$ in the US, to 55-70\% in Latin America and sub-Saharan Africa. ${ }^{31}$ Current treatment options include synthetic triazoles and allylamines that target sterol biosynthesis, and natural product-derived polyenes and echinocandins, which target the cell wall. However, they have very limited success in reducing high mortality rates of invasive fungal infections. ${ }^{31}$
According to the WHO, 8.2 million people die each year from cancer (13\% of all deaths worldwide).$^{32}$ Cancer represents the second leading cause of death in the US (WHO), and has also a significant impact in Brazil. National Institute of Cancer (INCA) estimates 600,000 new cases of cancer in Brazil during 2016-2017..$^{33}$ Cancer patients are at increased risk for invasive fungal infections, so better antifungal agents would form an important adjunct to cancer current treatments. Natural products have played a major role in the discovery and development of anticancer agents. Together with their semi-synthetic derivatives, natural products comprises $40 \%$ of 136 small molecules approved as anticancer drugs between 1981-2014. ${ }^{6}$

Chagas disease and leishmaniasis, designated as neglected tropical diseases (NTDs) by the WHO, are chronic protozoal infections that are typically endemic in low income countries. No effective treatment is currently available for Chagas disease, while the treatment of leishmaniasis is still incomplete. No single drug was approved by the any agency against Chagas disease or leishmaniasis between 1981-2014, ${ }^{6}$ except for miltefosine, originally approved as anticancer and then approved to treat leishmaniasis in $2006 .{ }^{34} \mathrm{~A}$ focus on new chemical series, excluding the drugs in current use, is required to promote the discovery of safe and efficacious treatments for leishmaniasis and Chagas disease. ${ }^{35}$ In addition, it has been recognized that collaborative drug discovery efforts, including public-private partnerships, are required to reduce the impact of infectious diseases in developing countries. ${ }^{35}$ The ICBG assembles academic expertise in the field of NTDs in Brazil with experience in partnership with Drugs for Neglected Diseases Initiative (DNDi). ${ }^{36,37}$

Screening natural products has special advantages for parasitic diseases, as well as other infectious and cancer, since the remarkable structural diversity of natural products can represent potential source of novel pharmacophores. ${ }^{38}$

\section{ICBG Legal Permits and Agreements}

ICBG research activities are approved by different permits from the Brazilian government, according to the Genetic Resources law. It is important to mention that the Brazilian ICBG was approved and started its activities prior to the Brazilian Genetic Resources Access Law 13.123/2015, which became effective on November, 2015, and has been regulated by the Presidential Decree 8.772 on May, 2016. ${ }^{39}$ Therefore, the permits required for the establishment of this international collaborative project might not be applied to new projects.

According to the new law, CGen (Conselho de Gestão do Patrimônio Genético, or Council of the Genetic Heritage 
Management), under the Ministry of Environment, created SISGen (Sistema Nacional de Gestão do Patrimônio Genético e do Conhecimento Tradicional Associado, or National System for the Genetic Heritage Management and Associated Traditional Knowledge) that will be used for registration of all scientific and technological activities related to the Biodiversity as well as for issuing permissions. Therefore, just one web system will be used to manage the Genetic Resources in Brazil, different from what had been in vigor before the new law. However, SISGen has not became public available yet.

According to the previous Brazilian Genetic Resources rules, effective during the establishment of the ICBG, different permits to different institutions should be applied. Research projects that aimed to collect and access genetic resources should initially apply for a collecting permit using the SISBIO electronic system supported by ICMBio (Instituto Chico Mendes de Conservação da Biodiversidade, or Chico Mendes Biodiversity Conservation Institute), an autarchy linked to the Ministry of Environment. All Brazilian and foreign researchers were registered in the system and listed in the SISBIO collecting permit. In order to access the genetic resources, i.e., getting information about natural products' structures and biological activities, an additional permit was applied for and approved by the CNPq (Conselho Nacional de Desenvolvimento Científico e Tecnológico, or National Council for Scientific Research and Technological Development), linked to the Ministry of Science, Technology and Innovation. The CNPq permit for the ICBG was issued on the basis of research project analysis and previous SISBIO collecting permit approval.

The ICBG project aims to collect and access genetic resources only in public areas located at National and State Parks, managed respectively by the Federal and State governments; therefore no additional agreements with landowners are required. The selected parks for collecting activities are preserved areas of biodiversity located in the major Brazilian biomes: Amazon, Atlantic Forest, Cerrado and Caatinga.

According to the previous Brazilian law requirements, an exporting license was required for each live genetic resources shipment to the US. The exporting license is issued by IBAMA (Instituto Brasileiro do Meio Ambiente e dos Recursos Naturais Renováveis, or Brazilian Institute of Environment and Renewable Natural Resources), another autarchy linked to the Ministry of Environment, through a specific web system. The exporting license specifies the number of species, taxonomic identification and type of vials the organisms will be exported in.

The Memorandum of Understanding (MoU) was an important document that was executed by all the research institutions: Harvard Medical School, University of Wisconsin-Madison, Dana Farber Cancer Institute, and School of Pharmaceutical Sciences of Ribeirão PretoUniversity of São Paulo. The agreement establishes all issues involved in the collaborative project and also includes the Material Transfer Agreement (MTA). The MTA was based on the previous document available in the $\mathrm{CNPq}$ website with some modifications specific for the ICBG project. After being signed by all research institutions representatives the MTA was approved by CNPq.

The ICBG work flow (Figure 1) could start as planned after these permits were approved and signed by the responsible institutions. It took one year to finalize all of the documentation.

\section{Conclusions}

Microbial natural products have a remarkable role in drug discovery, e.g. natural products and their semisynthetic derivatives account for $73 \%$ of antibacterial drugs approved by the US FDA or equivalent agencies in other countries, ${ }^{6}$ therefore microorganisms should still be considered in drug discovery programs. To increase the chances of finding new biologically active compounds, microorganisms from new ecological niches should be prioritized. Symbiosis between bacterial and insect hosts has been proven as a valuable source of new biological small molecules, especially exemplified by the fungusgrowing ants' multilateral symbiosis. Biologically active natural products from these symbiotic systems have not previously been studied in Brazil, and thus represent an untapped source of new molecules. The agreement between FAPESP and FIC/NIH created a remarkable opportunity to establish the current ICBG project in Brazil, aligning chemical ecology and therapeutic applications. The establishment of this cooperative group in Brazil illustrates that it is possible to conduct this type of project according to the legal requirements in place to protect Brazilian biodiversity. The interdisciplinary research team brings together different expertise in evolutionary biology, natural products chemistry and pharmacology, applying robust methods and strategies for the discovery of biologically active small molecules. Hopefully, we will be able to discover new useful natural products from the Brazilian bacterial symbionts of insects.

\section{Acknowledgments}

Authors are grateful to the National Institutes of Health (NIH grant U19TW009872) and São Paulo State Foundation (FAPESP grant 2013/50954-0) for the ICBG 
financial support. M. T. P. also acknowledges Coordenação de Aperfeiçoamento de Pessoal de Nível Superior (CAPES) and Conselho Nacional de Desenvolvimento Científico e Tecnológico (CNPq).

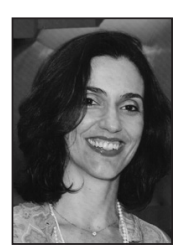

Mônica T. Pupo graduated in Pharmacy in 1990 from Universidade de São Paulo (USP), Ribeirão Preto campus, and then earned her PhD in Chemistry from Universidade Federal de São Carlos in 1997. She was a postdoctoral researcher at Instituto de Física de São Carlos, USP, for one year and then she joined the Faculdade de Ciências Farmacêuticas de Ribeirão Preto, USP, in 1998 as an Assistant Professor. She was appointed as Associated Professor in 2009. She was a visiting scholar at Professor Jon Clardy group (Harvard Medical School) from 2006 to 2007. Her research interests include the chemistry, biology and ecology of natural products from microbial symbionts.

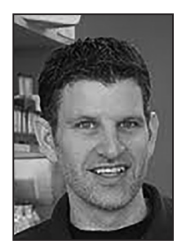

Cameron Currie received his BSc and MSc from the University of Alberta and his PhD from the University of Toronto. He is currently the Ira L. Baldwin Professor of Microbial Ecology and Evolution at the University of Wisconsin. His research focuses on the evolutionary ecology of symbiotic associations. He is especially interested in the role of symbiotic microbes as a source of evolutionary innovation, including in helping hosts deal with pathogens and parasites.

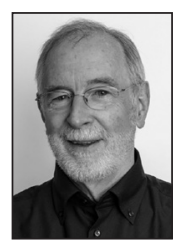

Jon Clardy obtained his BSc degree from Yale University and his $P h D$ from Harvard University. He has served on the faculties of Iowa State University, Cornell University, and Harvard Medical School where he is currently the Hsien Wu and Daisy Yen Wu Professor of Biological Chemistry and Molecular Pharmacology. His research has focused on naturally occurring biologically active small molecules, their macromolecular targets, and their roles in biology and medicine. He has won several prizes for his research and teaching.

\section{References}

1. https://www.fic.nih.gov/programs/pages/biodiversity.aspx, accessed in August 2016.

2. http://www.fapesp.br/en/8123, accessed in August 2016.

3. http://www.fapesp.br/en/8125, accessed in August 2016.
4. http://www.fapesp.br/en/8637, accessed in August 2016.

5. Clardy, J.; Walsh, C.; Nature 2004, 432, 829.

6. Newman, D. J.; Cragg, G. M.; J. Nat. Prod. 2016, 79, 629.

7. Douglas, A. E.; Dobson, A. J.; J. Chem. Ecol. 2013, 39, 1149.

8. Wilson, E. O.; The Insect Societies; Harvard University Press: Cambridge, USA, 1971.

9. Hölldobler, B.; Wilson, E. O.; The Ants; Harvard University Press: Cambridge, USA, 1990.

10. Schultz, T. R.; Brady, S. G.; Proc. Natl. Acad. Sci. USA 2008 , 105, 5435.

11. Currie, C. R.; Mueller, U. G.; Malloch, D.; Proc. Natl. Acad. Sci. USA 1999, 96, 7998.

12. Currie, C. R.; Scott, J. A.; Summerbell, R. C.; Malloch, D.; Nature 1999, 398, 701.

13. Cafaro, M. J.; Currie, C. R.; Can. J. Microbiol. 2005, 51, 441.

14. Ramadhar, T. R.; Beemelmanns, C.; Currie, C. R.; Clardy, J.; J. Antibiot. 2014, 67, 53.

15. Oh, D. C.; Poulsen, M.; Currie, C. R.; Clardy, J.; Nat. Chem. Biol. 2009, 5, 391.

16. Sit, C. S.; Ruzzini, A. C.; Van Arnam, E. B.; Ramadhar, T. R.; Currie, C. R.; Clardy, J.; Proc. Natl. Acad. Sci. USA 2015, 112, 13150.

17. Van Arnam, E. B.; Ruzzini, A. C.; Sit, C. S.; Currie, C. R.; Clardy, J.; J. Am. Chem. Soc. 2015, 137, 14272.

18. Carr, G.; Derbyshire, E. R.; Caldera, E.; Currie, C. R.; Clardy, J.; J. Nat. Prod. 2012, 75, 1806.

19. Mendes, T. D.; Borges, W. S.; Rodrigues, A.; Solomon, S. E.; Vieira, P. C.; Duarte, M. C. T.; Pagnocca, F. C.; BioMed Res. Int. 2013, article ID 835081.

20. Aanen, D. K.; Eggleton, P.; Rouland-Lefevre, C.; GuldbergFroslev, T.; Rosendahl, S.; Boomsma, J. J.; Proc. Natl. Acad. Sci. USA 2002, 99, 14887.

21. Um, S.; Fraimout, A.; Sapountzis, P.; Oh, D. C.; Poulsen, M.; Sci. Rep. 2013, 3, article No. 3250.

22. Kim, K. H.; Ramadhar, T. R.; Beemelmanns, C.; Cao, S. G.; Poulsen, M.; Currie, C. R.; Clardy, J.; Chem. Sci. 2014, 5, 4333.

23. Carr, G.; Poulsen, M.; Klassen, J. L.; Hou, Y. P.; Wyche, T. P.; Bugni, T. S.; Currie, C. R.; Clardy, J.; Org. Lett. 2012, 14, 2822.

24. Scott, J. J.; Oh, D.-C.; Yuceer, M. C.; Klepzig, K. D.; Clardy, J.; Currie, C. R.; Science 2008, 322, 63.

25. Oh, D. C.; Scott, J. J.; Currie, C. R.; Clardy, J.; Org. Lett. 2009, 11,633 .

26. Blodgett, J. A. V.; Oh, D. C.; Cao, S. G.; Currie, C. R.; Kolter, R.; Clardy, J.; Proc. Natl. Acad. Sci. USA 2010, 107, 11692.

27. Menezes, C.; Vollet-Neto, A.; Marsaioli, A. J.; Zampieri, D.; Fontoura, I. C.; Luchessi, A. D.; Imperatriz-Fonseca, V. L.; Curr. Biol. 2015, 25, 2851.

28. Paludo, C. R.; Ruzzini, A. C.; Silva-Junior, E. A.; Pishchany, G.; Currie, C. R.; Nascimento, F. S.; Kolter, R.; Clardy, J.; Pupo, M. T.; Genome Announc. 2016, 4, e00174-16.

29. Loewith, R.; Biochem. Soc. Trans. 2011, 39, 437. 
30. Fisher, M. C.; Henk, D. A.; Briggs, C. J.; Brownstein, J. S.; Madoff, L. C.; McCraw, S. L.; Gurr, S. J.; Nature 2012, 484, 186.

31. Brown, G. D.; Denning, D. W.; Gow, N. A. R.; Levitz, S. M.; Netea, M. G.; White, T. C.; Sci. Transl. Med. 2012, 4, 165rv13.

32. http://www.who.int/cancer/en/, accessed in August 2016.

33. http://www.inca.gov.br/estimativa/2016/index.asp?ID=2, accessed in August 2016.

34. Dorlo, T. P. C.; Balasegaram, M.; Beijnen, J. H.; de Vries, P. J.; J. Antimicrob. Chemother. 2012, 67, 2576.

35. Katsuno, K.; Burrows, J. N.; Duncan, K.; van Huijsduijnen, R. H.; Kaneko, T.; Kita, K.; Mowbray, C. E.; Schmatz, D.; Warner, P.; Slingsby, B. T.; Nat. Rev. Drug Discovery 2015, 14, 751.
36. Ferreira, L. G.; Oliveira, M. T.; Andricopulo, A. D.; Curr. Top. Med. Chem. 2016, 16, 2290.

37. Dias, L. C.; Dessoy, M. A.; Silva, J. J. N.; Thiemann, O. H.; Oliva, G.; Andricopulo, A. D.; Quim. Nova 2009, 32, 2444.

38. Pink, R.; Hudson, A.; Mouries, M. A.; Bendig, M.; Nat. Rev. Drug Discovery 2005, 4, 727.

39. http://www.planalto.gov.br/ccivil_03/_Ato2015-2018/2016/ Decreto/D8772.htm, accessed in August 2016.

Submitted: September 7, 2016

Published online: October 25, 2016

FAPESP has sponsored the publication of this article. 